\title{
Cinética do fósforo em tecidos de suínos alimentados com dietas contendo enzima fitase
}

\author{
[Phosphorus kinetics in tissue of growing pigs fed diets containing phytase enzyme] \\ J.A. Moreira ${ }^{1}$, D.M.S.S. Vitti ${ }^{1}$, J.B. Lopes $^{2}$, M.A. Trindade Neto ${ }^{3}$ \\ ${ }^{1}$ Universidade de São Paulo \\ Centro de Energia Nuclear na Agricultura (CENA) \\ Avenida Centenário, 303, Caixa Postal 96 \\ 1340-970 - Piracicaba, SP \\ ${ }^{2}$ Universidade Federal do Piauí-Campus Universitário de Socopo-Teresina \\ ${ }^{3}$ Faculdade de Medicina Veterinária e Zootecnia - USP - Pirassununga
}

\section{RESUMO}

$\mathrm{O}$ experimento foi desenvolvido para avaliar a cinética do $\mathrm{P}$ em tecidos de suínos em crescimento, alimentados com rações contendo $\mathrm{P}$ orgânico e vários níveis de fitase, com o uso do ${ }^{32} \mathrm{P}$ como indicador. Foram usados 12 animais mestiços, machos castrados, com peso médio de 31,68土1,62kg, distribuídos em um delineamento inteiramente ao acaso, em esquema de parcela subdividida, contendo quatro tratamentos $(253,759,1265$ e 1748 UF (unidade de fitase) $/ \mathrm{kg}$ ) e três repetições. Os tratamentos foram constituídos de níveis de inclusão da enzima fitase nas dietas associados aos tecidos dos ossos, fígado, coração, rins e músculos. Os leitões foram mantidos em gaiolas metabólicas por um período de dez dias de adaptação e sete dias de coletas de sangue. No primeiro dia de coleta, foram injetados em cada animal, por via endovenosa, 7,4 MBq de ${ }^{32} \mathrm{P}$, como indicador. No final do período experimental os animais foram sacrificados e amostras dos tecidos coletadas. Os níveis da enzima fitase não interferiram na retenção de ${ }^{32} \mathrm{P}$ nos tecidos e nas trocas plasmáticas dos mesmos. A ação da enzima fitase ocorreu, principalmente, na concentração de P nos rins, sendo sua atuação mais efetiva nos níveis entre 253 e 759 UF/kg de ração; o maior intercâmbio do fósforo em suínos alimentados com dietas contendo diferentes níveis de fitase ocorreu entre os rins e o plasma.

Palavras-chave: cálcio, diluição isotópica, fitato, nutrição, radionuclídeo

\begin{abstract}
The research was carried out to study the kinetic of $P$ in tissues of pigs fed rations containing organic $P$ with the addition of different levels of phytase enzyme, using the ${ }^{32} P$ as a metabolic tracer. Twelve crossbred barrow with $31,68 \pm 1,62 \mathrm{~kg}$ were divided in a completely randomized design in a split plot arrangement, with four treatments (253, 749, 1265 and $1748 \mathrm{PU}$ (phytase unit)/kg) and three repetitions. Treatments formed the parcels and tissues (bones, liver, heart, kidneys and muscles) the by-parcels. All pigs were kept in a metabolic cage for a seven-day period for sample collection. At the first day of the collection period, each animal was injected intravenously with $7.4 \mathrm{MBq}$ of ${ }^{32} \mathrm{P}$. On the seventh day all animals were slaughtered and samples of tissues were collected. The phytase enzyme affected the concentration of $P$ in kidney at the levels of 253 and $759 \mathrm{PU} / \mathrm{kg}$.
\end{abstract}

Keywords: calcium, isotopic dilution, nutrition, phytato, radionuclide

Projeto FAPESP 98/05562-5

Recebido para publicação em 16 de maio de 2003

Recebido para publicação, após modificações,em 24 de outubro de 2003

E-mail: japmoreira@bol.com.br 


\section{INTRODUÇÃO}

Os animais monogástricos não sintetizam a enzima fitase, tendo como conseqüência a baixa eficiência no aproveitamento do fósforo de origem vegetal, uma vez que 25 a $30 \%$ desse mineral ficam disponíveis para o organismo. Como o fósforo é um mineral essencial, por desempenhar importantes funções nos processos metabólicos, ao se formularem rações para suínos, torna-se necessário adicionar uma fonte de fósforo inorgânico.

O fosfato bicálcico e a farinha de ossos constituem as principais fontes de fósforo, tradicionalmente utilizadas na nutrição de suínos. A farinha de ossos foi o primeiro produto utilizado como fonte de fósforo, porém, seu emprego é restrito, principalmente, em função de sua composição variável, problemas de contaminação por microorganismos e oferta limitada (Lopes, Tomich, 2001). O fosfato bicálcico é um produto de excelente qualidade, mas de custo muito elevado, sobrecarregando ainda mais o preço das rações, que representa cerca de $70 \%$ do custo de um animal terminado.

O fósforo é considerado um agente poluidor, pois do total consumido pelos animais monogástricos, cerca de 70 a $75 \%$ são excretados nas fezes e urina (Oliveira, 2001).

A enzima fitase, quando adicionada nas rações, atua nas ligações do grupo fosfato, liberando o fósforo e outros minerais, que fazem parte desta molécula (Cromwell, 1991). Os primeiros estudos desenvolvidos com a enzima fitase, apesar de promissores, tiveram como entrave o alto custo no processo de obtenção do produto. Porém, com o avanço da tecnologia de fermentação, a fitase vem sendo comercializada industrialmente, o que tem despertado maior interesse de diversos nutricionistas preocupados com o alto custo do fósforo inorgânico e com a poluição ambiental (Cromwell et al., 1995; Moreira et al., 2000; Moreira et al., 2001).

$\mathrm{O}$ uso de radionuclídeo como ${ }^{32} \mathrm{P}$ pode indicar a distribuição e as trocas entre tecidos e fluidos e quantificar a concentração desse mineral nos tecidos corporais, como resposta do seu metabolismo ao suprimento dietético. Isto pode ser obtido pela determinação da concentração de
$\mathrm{P}$ e da taxa de retenção do ${ }^{32} \mathrm{P}$ e pelas atividades específicas relativas e padronizadas nos órgãos e tecidos, através da técnica de diluição de isótopos (Lopes, 1998).

A técnica fundamenta-se na constatação de que ao injetar o material radioativo na corrente sangüínea dos animais, os átomos dos isótopos estáveis, de origem alimentar, se associam aos átomos dos isótopos radioativos, distribuindo-se de maneira homogênea, permitindo o rastreamento do mineral pelos tecidos dos animais, caracterizado pela radioatividade em cada compartimento do organismo (AbouHussein et al., 1968).

A incorporação do fósforo nos vários tecidos e órgãos é variável e dependente da taxa de renovação e da fase de crescimento do animal. A troca desse mineral nos tecidos decresce com a idade e aumenta durante os períodos de atividade reprodutiva, sendo essas trocas mais intensas no fósforo lábil do esqueleto e na matéria esponjosa do osso (Georgievskii, 1982).

A atividade específica padronizada avalia a incorporação do ${ }^{32} \mathrm{P}$ nos tecidos, ou seja, a substituição do $\mathrm{P}$ estável pelo $\mathrm{P}$ radioativo, levando em consideração a correlação da dose da atividade injetada para o peso dos animais (Lopes et al., 1999).

A atividade específica relativa expressa a taxa metabólica do $\mathrm{P}$ através da relação entre atividade específica (relação entre átomos estáveis e radioativos) no plasma e tecidos. As atividades específicas no plasma e nos fluídos extracelulares, após a aplicação do radiotraçador, são mais elevadas do que nas células, mas o intercâmbio do elemento entre os compartimentos faz com que a atividade específica dos tecidos aumente até se igualar com o plasma, quando o valor da atividade específica relativa será igual a um (Bueno, 1997).

O presente estudo destinou-se a avaliar a cinética do fósforo absorvido nos tecidos de suínos na fase de crescimento e os efeitos da inclusão de níveis crescentes da enzima fitase, em dietas à base de milho, farelo de soja e óleo de soja, contendo $17,5 \%$ de farelo de arroz desengordurado. 


\section{Moreira et al.}

\section{MATERIAL E MÉTODOS}

Foram utilizados 12 leitões mestiços, machos castrados, com peso médio de $31,68 \pm 1,62 \mathrm{~kg}$. Os tratamentos consistiram dos níveis de enzima fitase, $0,253,759,1265$ e $1748 \mathrm{UF} / \mathrm{kg}$ de ração, correspondendo a 0,$00 ; 0,011 ; 0,033 ; 0,055$ e $0,076 \%$, respectivamente, como base de cálculo para as rações e foram distribuídos em delineamento inteiramente ao acaso e parcela subdividida.

Os níveis de inclusão da enzima fitase nas dietas representaram as parcelas e os tecidos dos ossos (costela), rins, fígado, coração e músculos (lombo) as subparcelas, sendo a unidade experimental representada por um suíno alojado em gaiola de estudo metabólico.

A enzima fitase (allzyme phytase) utilizada no experimento foi produzida a partir de fungos do grupo Aspergillus niger, contendo também celulase, protease, xylanase e fosfatase ácida, possuindo atividade declarada de 2300 unidades de fitase por grama (UF/g). A unidade de fitase, representando a quantidade de enzima que libera $1 \mu \mathrm{mol}$ de fósforo inorgânico do fitato de sódio em um minuto, em condições padrão, foi determinada num substrato de sódio-fitato a $37^{\circ} \mathrm{C}$ e pH 5,5. A indicação do fabricante é que se use cerca de $500 \mathrm{~g}$ desse produto por tonelada de ração, correspondendo a 1150 UF/kg de ração.

A composição percentual das rações de crescimento encontra-se na Tab. 1, formuladas para atender às exigências dos suínos na fase de crescimento, de acordo com Nutrient... (1998) e Rostagno et al. (2000), exceto para o fósforo.

Tabela 1. Composição percentual das rações para suínos em fase de crescimento

\begin{tabular}{lcccc}
\hline \multirow{2}{*}{ Ingrediente } & \multicolumn{4}{c}{ Nível de fitase (UF/kg de dieta) } \\
\cline { 2 - 5 } Milho & 253 & 759 & 1265 & 1748 \\
Farelo de arroz desengordurado & 61,64 & 61,62 & 61,60 & 61,57 \\
Óleo vegetal & 17,50 & 17,50 & 17,50 & 17,50 \\
Farelo de soja & 1,60 & 1,60 & 1,60 & 1,60 \\
Fosfato bicálcico & 17,00 & 17,00 & 17,00 & 17,00 \\
Calcário & 0,00 & 0,00 & 0,00 & 0,00 \\
Sal & 1,40 & 1,40 & 1,40 & 1,40 \\
Premix vitamínico & 0,35 & 0,35 & 0,35 & 0,35 \\
Premix mineral & 0,40 & 0,40 & 0,40 & 0,40 \\
Enzima fitase & 0,10 & 0,10 & 0,10 & 0,10 \\
Valores calculados: & 0,011 & 0,033 & 0,055 & 0,076 \\
Energia digestível (kcal/kg) & 3279 & 3279 & 3279 & 3279 \\
Proteína bruta, \% & 17,30 & 17,30 & 17,30 & 17,30 \\
Cálcio, \% & 0,61 & 0,61 & 0,61 & 0,61 \\
Fósforo total, \% & 0,74 & 0,74 & 0,74 & 0,74 \\
Fósforo disponível, \% & 0,22 & 0,22 & 0,22 & 0,22 \\
\hline a Quantidades por kg de suplemento: vit. A - 1500000 UI; vit. $\mathrm{D}_{3}-255000 \mathrm{UI}$; vit. E - 3000mg; vit. K - 500mg; tiamina - 2500mg; \\
riboflavina - 750mg; piridoxina - 250mg; vit $\mathrm{B}_{12}-$ 3000mcg; pantotenato de calcio - 3750mg; niacina - 5500mg; antioxidante - \\
6,25g; promotor de crescimento - 6,25g; cloreto de colina - 75g; selênio - 22,5mg. & & \\
${ }^{b}$ Quantidades por kg de ração: Mn - 45mg; Cu - 15mg - Zn, 80mg; Fe - 88mg; I - 1mg. & &
\end{tabular}

Os leitões foram alojados em gaiolas de estudo metabólico por um período de 17 dias, sendo 10 pré-experimentais e sete correspondentes à fase de coleta. No primeiro dia da fase experimental os suínos receberam por via endovenosa, 7,4 $\mathrm{MBq}$ de ${ }^{32} \mathrm{P}$ e no sétimo dia eles foram sacrificados e amostras de ossos, fígado, coração, rins e músculos foram retiradas.
As análises bromatológicas das dietas foram realizadas de acordo com as recomendações da Official... (1980). Na determinação do $\mathrm{P}$ inorgânico do plasma e dos tecidos seguiu-se o método descrito por Fiske e Subbarow (1925) e o cálcio foi determinado por espectrofotometria de absorção atômica (Zagatto et al., 1979). A atividade do material radioativo foi determinada 
pelo efeito Cerenkov, em espectrômetro de cintilação líquida (Nascimento Filho, Lobão, 1977). O teor de P nas dietas foi calculado pelo método vanadato-molibdato (Sarruge, Haag, 1974) e os cálculos das atividades específicas $\left({ }^{32} \mathrm{P} / \mathrm{P}\right.$ total) foram realizados conforme Lofgreen (1960).

Nos tecidos dos ossos, fígado, coração, rins e músculos foram calculadas a retenção de ${ }^{32} \mathrm{P}$ [(cpm da amostra do tecido/g de MS $\div$ dose total injetada) $/(\mathrm{mg} \mathrm{P} / \mathrm{g} \mathrm{MS})]$, a atividade específica padronizada [(cpm da amostra do tecido/g de $\mathrm{MS} \div \mathrm{mg} \mathrm{P} / \mathrm{g} \mathrm{MS}) /(\mathrm{cpm}$ da dose injetada $\div \mathrm{kg}$ de peso do animal)] e a atividade específica relativa (atividade específica do tecido/atividade específica do plasma).

Utilizaram-se análise de variância e teste t para comparar médias entre os tecidos e análise de regressão por polinômios ortogonais para avaliar os efeitos da enzima em cada tecido após a absorção do P e Ca, utilizando o PROC GLM do Applications... (1991).

\section{RESULTADOS E DISCUSSÃO}

Os resultados da concentração de $\mathrm{P}$ inorgânico nos tecidos, de acordo com o nível da enzima fitase, encontram-se na Tab. 2. Os níveis de fitase não influenciaram a concentração de $\mathrm{P}$ inorgânico nos tecidos dos ossos, fígado, coração e músculos, entretanto, nos rins, observou-se uma relação quadrática, representada pela equação, $\hat{\mathrm{Y}}=14,5400-486,9420 \mathrm{X}+$ $6261,9024 \mathrm{X}^{2}, \mathrm{R}^{2}=0,81 \quad(\mathrm{P}<0,05)$, demonstrando diminuição da concentração do $\mathrm{P}$ nos rins com o incremento dos níveis de fitase na ração até 894 UF (ponto de mínimo). De acordo com Cromwell (1991), a fitase promove a catálise do fitato liberando o fósforo e outros minerais para o metabolismo dos animais. Este processo ocorre nos intestinos. Entretanto, observa-se que a fitase também interfere no aproveitamento do fósforo após a sua absorção.

Tabela 2. Variáveis relacionadas com a cinética do P nos tecidos de suínos em crescimento

\begin{tabular}{lccccc}
\hline \multirow{2}{*}{ Variável } & \multicolumn{5}{c}{ Tecido $(\mathrm{mg} / \mathrm{g}$ MS $)$} \\
\cline { 2 - 6 } & Ossos & Fígado & Coração & Rins & Músculos \\
\hline Concentração P & $75,35 \pm 5,10 \mathrm{a}$ & $8,15 \pm 1,30 \mathrm{~b}$ & $6,64 \pm 1,74 \mathrm{~b}$ & $8,91 \pm 2,92 \mathrm{~b}$ & $7,35 \pm 1,79 \mathrm{~b}$ \\
Concentração Ca & $83,02 \pm 11,4 \mathrm{a}$ & $0,21 \pm 0,03 \mathrm{~b}$ & $0,32 \pm 0,14 \mathrm{~b}$ & $0,22 \pm 0,05 \mathrm{~b}$ & $0,20 \pm 0,02 \mathrm{~b}$ \\
Relação Ca/P & $1,10 \pm 0,12 \mathrm{a}$ & $0,03 \pm 0,00 \mathrm{~b}$ & $0,05 \pm 0,01 \mathrm{~b}$ & $0,03 \pm 0,01 \mathrm{~b}$ & $0,03 \pm 0,01 \mathrm{~b}$ \\
${ }^{32}$ P Retido & $0,01 \pm 0,00 \mathrm{a}$ & $0,012 \pm 0,00 \mathrm{ab}$ & $0,010 \pm 0,00 \mathrm{ab}$ & $0,013 \pm 0,00 \mathrm{ab}$ & $0,015 \pm 0,01 \mathrm{~b}$ \\
A. E. Padronizada & $0,30 \pm 0,01 \mathrm{a}$ & $0,39 \pm 0,05 \mathrm{~b}$ & $0,32 \pm 0,05 \mathrm{ab}$ & $0,41 \pm 0,02 \mathrm{bd}$ & $0,32 \pm 0,02 \mathrm{ab}$ \\
A E. Relativa & $0,37 \pm 0,02 \mathrm{a}$ & $0,49 \pm 0,06 \mathrm{~b}$ & $0,41 \pm 0,07 \mathrm{abc}$ & $0,51 \pm 0,04 \mathrm{bd}$ & $0,40 \pm 0,05 \mathrm{abc}$ \\
\hline
\end{tabular}

Médias, seguidas de letras distintas na linha diferem entre si $(\mathrm{P}<0,05)$ pelos testes $\mathrm{F}$ e t.

A concentração do fósforo nos tecidos do fígado, coração, rins e músculos, apresentou valores semelhantes $(\mathrm{P}>0,05)$, enquanto a dos ossos foi superior à dos demais tecidos $(\mathrm{P}<0,05)$, o que está de acordo com as observações de Vitti et al. (1992), estudando a cinética do fósforo em tecidos de ovinos e as de Figueirêdo et al. (1998) e Lopes et al. (1999), em pesquisa com suínos.

Os ossos, segundo Maynard et al. (1984), são caracterizados como os sítios de maior concentração do fósforo, chegando a mobilizar cerca de 75 a $85 \%$ do total. Para os tecidos moles, Georgievskii (1982) destacou que o conteúdo do fósforo pode variar entre 15 a $25 \mathrm{mg} / \mathrm{g}$ de tecido, no músculo esquelético, 10 a
$16 \mathrm{mg} / \mathrm{g}$ de tecido, nos rins, 15 a $27 \mathrm{mg} / \mathrm{g}$ de tecido, no coração e 18 a $26 \mathrm{mg} / \mathrm{g}$ de tecido no fígado, sendo esses valores superiores aos observados neste experimento para os mesmos tecidos. Os valores obtidos também foram inferiores aos de Smith et al. (1951), Figueirêdo (1998) e Lopes (1998), cujas diferenças, provavelmente, estão associadas ao metabolismo dos animais, graças a fatores como peso, idade, genética e estado nutricional.

Os níveis de enzima fitase na ração não afetaram $(\mathrm{P}>0,05)$ a concentração do cálcio nos tecidos estudados, indicando que a enzima não interferiu na distribuição desse mineral após a sua absorção. O conteúdo do cálcio nos tecidos do 


\section{Moreira et al.}

fígado, coração, rins e músculos foi semelhante $(\mathrm{P}>0,05) \quad$ (Tab.2), entretanto, os ossos apresentaram maior concentração $(\mathrm{P}<0,05)$.

A ordem decrescente da retenção do cálcio nos tecidos foi: ossos, coração, rins, fígado $\mathrm{e}$ músculos, caracterizando os ossos como o maior órgão de retenção desse mineral. De acordo com Maynard e Loosli (1966), 99\% do cálcio encontram-se nos ossos e dentes, e o restante nos demais tecidos, sendo amplamente distribuído através de todo sistema, participando da contração muscular, da coagulação do sangue e do metabolismo de energia (Penz Junior, Viola, 1998).

Também não se observou efeito dos níveis crescentes da enzima fitase na ração sobre a relação cálcio:fósforo nos tecidos $(\mathrm{P}>0,05)$, indicando que a enzima fitase não exerceu efeito sobre a distribuição do cálcio e do fósforo após a sua absorção. Entretanto, estudos mais detalhados utilizando o radionuclídeo ${ }^{45} \mathrm{Ca}$ são necessários para se avaliar a cinética do cálcio de origem alimentar, pois o presente estudo permite identificar apenas o efeito da deposição geral sobre os tecidos. A relação Ca:P nos ossos (Tab. 2) apresentou valores abaixo dos $2: 1$, normalmente encontrados na literatura (Lopes, 1998). Isto ocorreu, provavelmente, graças à idade dos animais. Entretanto, a taxa recomendada para esta relação nas dietas de suínos é baseada na fisiologia do próprio animal, sendo em torno de 1,5:1, o que corresponde ao valor encontrado no leite das porcas (Peo Junior et al., 1991). Segundo o Nutrient... (1998), com base no fósforo disponível, essa relação pode variar entre $2: 1$ e $3: 1$.

A retenção do ${ }^{32} \mathrm{P}$ nos tecidos não sofreu influência dos níveis da enzima fitase nas dietas $(\mathrm{P}>0,05)$. Os valores de $\mathrm{P}$ incorporado nos tecidos dos ossos, fígado, coração e rins não diferiram entre si $(\mathrm{P}>0,05)$. Os ossos apresentaram menor incorporação de ${ }^{32} \mathrm{P}$ que os músculos $(\mathrm{P}<0,05)$ (Tab. 2). Esta constatação está em consonância com os resultados encontrados por Figueirêdo (1998) e Lopes et al. (1999). A velocidade das trocas entre o fósforo do plasma e das células ósseas é mais lenta do que nos demais tecidos, entretanto, o tecido ósseo é o órgão de maior mobilização desse mineral (Figueirêdo, 1998). Dessa maneira, a baixa retenção desse mineral encontrada nos ossos reflete a influência do período experimental, que foi curto.

Os dados para incorporação de ${ }^{32} \mathrm{P}$ nos ossos são divergentes dos observados por Vitti et al. (1992) e Bueno (1997), que encontraram maior retenção de ${ }^{32} \mathrm{P}$ nos ossos de ovinos. Segundo Figueirêdo (1998), vários fatores como espécie, fase de crescimento, intervalo de aplicação do ${ }^{32} \mathrm{P}$ e coleta de amostras e, principalmente a duração do período experimental e o estado nutricional do animal podem interferir no intercâmbio do fósforo das células dos tecidos com o plasma e fluídos intersticiais.

A atividade específica padronizada nos tecidos não foi influenciada pelos níveis da enzima fitase na dieta $(\mathrm{P}>0,05)$, decrescendo na seguinte ordem: rins, fígado, coração, músculos e ossos, sendo o maior valor observado para os rins e o menor para os ossos $(\mathrm{P}<0,05)$ (Tab. 2). Os resultados do presente estudo diferem dos observados por Smith et al. (1951), quando constataram que a atividade específica padronizada decresceu na ordem: fígado, rins, coração e músculos, e, em parte, assemelham-se aos obtidos por Figueirêdo (1998) e Lopes et al. (1999) em pesquisas com suínos, ao encontrarem menor valor para os ossos e maior para os rins. Smith et al. (1952) constataram em tecidos de ovinos a seguinte ordem decrescente: rins, coração, músculos, fígado e ossos, enquanto Bueno (1997), ao trabalhar com caprinos, observou a ordem: rins, coração, fígado, músculos e ossos. Assim, a análise desses trabalhos mostra que a menor mobilização do fósforo ocorreu nos ossos e a maior nos rins, sugerindo que estes são os locais de maior intercâmbio do fósforo com o plasma e os fluidos intersticiais. Entretanto, apesar de ser um dos locais de maior mobilização do $\mathrm{P}$, os ossos apresentaram valor inferior aos demais tecidos. Isto demonstra que as trocas entre as células dos ossos com o plasma são mais lentas.

Os valores da atividade específica relativa não foram influenciados pelos níveis crescentes de enzima fitase $(\mathrm{P}>0,05)$. A atividade específica relativa representa a relação entre $\mathrm{P}$ estável e $\mathrm{P}$ radioativo entre os tecidos e o plasma. Dessa forma, com a absorção do $\mathrm{P}$ de origem alimentar, o plasma, que contém o $\mathrm{P}$ radioativo, fica mais concentrado do que os tecidos, nos quais a incorporação mineral ocorre conforme a 
exigência metabólica. Como a relação entre $\mathrm{P}$ radioativo e estável é constante e o metabolismo é idêntico, valores maiores significam maior incorporação do $\mathrm{P}$ de origem alimentar nos tecidos. A ausência de efeitos $(\mathrm{P}>0,05)$ dos tratamentos sobre essa variável demonstra que a fitase não interferiu na cinética do fósforo nos tecidos dos suínos após a sua absorção. Os maiores valores observados nos rins e fígado $(\mathrm{P}<0,05)$ (Tab. 2), caracterizam a mobilização mais rápida do fósforo do que nos demais órgãos (ossos, músculos e coração). O menor valor observado para os ossos, comparado aos tecidos dos rins e fígado, sugere que nos tecidos com menor teor de fósforo, como os tecidos moles, as trocas são mais intensas porque primeiro o nutriente atende às exigências dos tecidos e depois é incorporado aos ossos.

\section{CONCLUSÕES}

Os níveis da enzima fitase não interferem na retenção de ${ }^{32} \mathrm{P}$ nos tecidos dos ossos, fígado, coração, rins e músculos, e nas respectivas trocas plasmáticas. A ação da enzima fitase ocorre, principalmente, na concentração de $\mathrm{P}$ nos rins, sendo sua atuação mais efetiva nos níveis entre 253 e 759 UF/kg de ração. O maior intercâmbio do fósforo em suínos alimentados com dietas contendo diferentes níveis de fitase ocorre entre os rins e o plasma.

\section{REFERÊNCIAS BIBLIOGRÁFICAS}

ABOU-HUSSEIN, E.R.M.; RAAFAT, M.A.; EL GINDI, I.M. et al. Metabolism of ${ }^{32} \mathrm{P}$ in sheep. Pakistan J. Scient. Res., v.20, p.28-33, 1968.

APPLICATIONS guide. 11.ed. Cary, NC: SAS Institute, 1991. 380p.

BUENO, S.M. Niveis de fósforo para caprinos: metabolismo, cinética e digestibilidade aparente. Piracicaba. 1997. 57f. Tese (Doutorado). Centro de Energia Nuclear na Agricultura, Universidade de São Paulo, Piracicaba, SP.

CROMWELL, G.L. Phytase appears to reduce phosphorus in feed, manure. Feedstuffs, v.63, p.41, 1991 .

CROMWELL, G.L.; COFFEY, R.D.; MONEGUE, H.J.; RANDOLPH, J.H. Efficacy of low-activity, microbial phytase in improving the bioavailability of phosphorus in cornsoybean meal diets for pigs. J. Anim. Sci., v.73, p.449-456, 1995.

FIGUEIRÊDO, A.V. Disponibilidade biológica de fósforo de cinco fosfatos, determinada com suínos em crescimento, através da técnica de diluição isotópica. Piracicaba. 1998. 103f. Tese ( Doutorado) - Centro de Energia Nuclear na Agricultura, Universidade de São Paulo, Piracicaba, SP.

FIGUEIRÊDO, A.V.; VITTI, D.M.S.S.; LOPES, J.B. Cinética do radiofósforo em tecidos de suínos em crescimento, alimentados com dietas contendo diferentes fontes fosfatadas. In: REUNIÃO ANUAL DA SOCIEDADE BRASILEIRA DE ZOOTECNIA, 35., 1998, Botucatu. Anais..., Botucatu, 1998, p.207-209. (Resumo).

FISKE, C.H., SUBBARROW, Y. The colorimetric determination of phosphorus. $J$. Biol. Chem., v.66, p.375-400, 1925.

GEORGIEVSKII, V.I. The physiological role of macroelements. In: GEORGIVIESKII, V.I.; ANNENKOV. B.N.; SAMOKHIN V.T. Mineral nutrition of animals. 1.ed. London: Butterworths, 1982. p.91-170.

LOFGREEN, G.P. The availabiliity of the phosphorus in dicalcium phosphate, bone, meal, soft phosphate and calcium phytates for mature wethers. J. Nutr., v.70, p.58-62, 1960.

LOPES, H.O.S.; TOMICH, T.R. Avanços recentes na nutrição mineral de bovinos. Piracicaba:Fealq, 2001. p.205-234

LOPES, J.B. Avaliação da absorção real e das perdas endógenas de fósforo em suínos pela técnica de diluição isotópica. Piracicaba. 1998. 87f. Tese (Doutorado) - Centro de Energia Nuclear na Agricultura, Universidade de São Paulo, Piracicaba, SP.

LOPES, J.B.; VITTI, D.M.S.S.; FIGUEIRÊDO, A.V. et al. Cinética do fósforo em tecidos de suínos em crescimento. Rev. Bras. Zootec., v.28, p.779-784, 1999.

MAYNARD, L.A.; LOOSLI, J.L. Nutrição animal. Rio de Janeiro: USAID, 1966. 550p.

MAYNARD, L.A.; LOOSLI,J.K.; HINTZ, H.F. Nutrição animal. 3.ed. Rio de Janeiro: Livraria Freitas Bastos, 1984. 726p. 


\section{Moreira et al.}

MOREIRA, J.A.; VITTI, D.M.S.S.; LOPES, J.B. Estudo dos efeitos da enzima fitase em rações para suínos através do radiofósforo - P-32. In: REUNIÃO ANUAL DA SOCIEDADE BRASILEIRA DE ZOOTECNIA, 37., Viçosa, 2000. Anais..., Viçosa, 2000. p.292. (Resumo).

MOREIRA, J.A.; VITTI, D.M.S.S.; TRINDADE NETO, M.A. et al. J.B. Enzima fitase e farelo de arroz desengordurado para suínos. In: REUNIÃO ANUAL DA SOCIEDADE BRASILEIRA DE ZOOTECNIA, 38., Piracicaba, 2001. Anais..., Piracicaba, 2001. p.703-704. (Resumo).

NASCIMENTO FILHO, V.F.; LOBÃO, A.O. Detecção de P-32 em amostras de origem animal e vegetal por efeito Cerenkov, cintilação líquida $e$ detector GM. Piracicaba:CENA, 1977. 25p. (Boletim Científico, 48).

NUTRIENT requirements of swine. 10.ed. Washington: NRC, 1998. 189p.

OFFICIAL methods of analysis. 13.ed. Washington: AOAC, 1980. 1018p.

OLIVEIRA, P.A.V. Produção e manejos de dejetos de suínos. In: REUNIÃO ANUAL DA SOCIEDADE BRASILEIRA DE ZOOTECNIA, 38., Piracicaba, 2001. Anais..., Piracicaba, 2001. p.164-177. (Resumo).

PENZ JUNIOR, A.M.; VIOLA, E.S. Nutrição. In: SOBESTIANSKY, J.; WENTZ, I.; SILVEIRA, P.R.S. et al. Suinocultura intesiva. EMBRAPA-CNSPSa, 1998. cap.3, 388p.

PEO JÚNIOR, E.R. Calcium, phosphorus and vitamin D in swine nutrition. In: MILLER, E.R.;
ULTREY, D.E.; LEWIS, A.J. Swine nutrition. Boston: Butterworth-Heinemann, 1991. p.165182.

ROSTAGNO, H.S; ALBINO, L.F.T.; DONZELE, J.L. et al. Composição de alimentos $e$ exigências nutricionais de aves e suínos: tabelas brasileiras. Viçosa: Imprensa Universitária, 2000. 141p.

SARRUGE, J.R., HAAG, H.P. Análises químicas em plantas. Piracicaba: ESALQ/USP, 1974. 56p.

SMITH, A.H.; KLEIBER, M.; BLACK, A.L. et al. Distribution of intravenously injected radioactive phosphorus $\left({ }^{32} \mathrm{P}\right)$ among swine tissues. J. Anim. Sci., v.10, p.893-901, 1951.

SMITH, A.H.; KLEIBER, M.; BLACK, A.L. et al. Distribution of intravenously injected radioative phosphorus $\left({ }^{32} \mathrm{P}\right)$ among sheep tissues. J. Anim. Sci., v.11, p.638-645, 1952.

VITTI, D.M.S.S.; ABDALLAS, A.L.; MEIRELLES, C.F. Cinética do fósforo em ovinos suplementados com diferentes fontes fosfatadas, através da técnica de diluição isotópica. Arq. Bras. Med. Vet. Zootec., v.44, p.227-233, 1992

ZAGATTO, E.A.G.; KRUG, F.J.; BERGAMIN FILHO, H. et al. Merzing in flow injection analasis. Part 2. Determination of calcium, magnesium and potassium in plant material by flow injection atomic and flame emission spectrometry. Anal. Chim. Acta, v.104, p.279284, 1979. 